\title{
Avaliação qualitativa entre as radiografias cefalométricas laterais digital e convencional
}

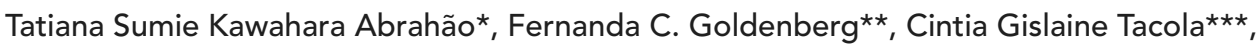
Eduardo Kazuo Sannomiya****

\section{Resumo}

Objetivos: avaliar, por meio do traçado cefalométrico e medidas cefalométricas, a dificuldade na localização das estruturas e dos pontos, tanto na radiografia convencional quanto na digital. Metodologia: a amostra constituiu-se de 30 telerradiografias em norma lateral, sendo 15 convencionais e 15 digitais. Essas radiografias foram obtidas de 15 indivíduos brasileiros, adultos, sendo que de cada paciente obteve-se uma radiografia convencional e uma digital. Resultados: com base nos dados obtidos, observou-se que não houve diferença estatisticamente significativa quando comparados os dois métodos de estudo. Conclusões: sendo assim, concluiu-se que, independentemente do método aplicado, o indivíduo que realiza o traçado, seja manual ou por meio de programas de computador, tanto na radiografia convencional quanto na digital, deve estar treinado e calibrado para a execução do mesmo.

Palavras-chave: Telerradiografias. Radiografia convencional. Radiografia digital.

\section{INTRODUÇÃO}

Há quase um século, a utilização de filmes radiográficos tem sido o único meio para a realização de radiografias intra e extrabucais. A introdução dos métodos digitais de obtenção das imagens forneceu infinitas possibilidades de processamento e análise das imagens radiográficas. Os sistemas digitais podem ser realizados de duas formas: direta ou indiretamente. Essa última é obtida a partir da radiografia convencional, utilizando scanners ou máquinas digitais. A desvantagem é que esse sistema requer o processamento do filme radiográfico, aparelhos digitalizadores sofisticados e tempo para digitalizar o filme radiográfico.
No método digital direto, a imagem se torna visível por um sistema receptor de imagem digital, onde, nos casos mais simples, o filme radiológico é substituído por um sensor digital ou uma placa de fósforo, sem que sejam necessárias modificações no aparelho de raios X. No sistema com sensores de semicondutores, a imagem é capturada diretamente em um sensor, que está conectado a um computador; portanto, a imagem fica disponível imediatamente ao operador. No sistema com placas de fósforo fotoativadas a imagem fica arquivada nessa placa e, no manuseio junto ao paciente, quase não existe diferença com relação aos métodos convencionais. Estas placas são escaneadas, após a

* Aluna do programa de pós-graduação em Odontologia (mestrado) - área de Concentração em Ortodontia - da UMESP.

** Professora titular da disciplina de Ortodontia da UMESP. Professora doutora do programa de pós-graduação em Odontologia (mestrado) - área de concentração em Ortodontia - da UMESP.

*** Tecnóloga em Radiologia Médica - Faculdade de Saúde/Universidade São Camilo. Especialista em Imagem e Produtos NDT/FUJI FILM.

**** Professor titular da disciplina de Imaginologia e Radiologia Odontológica da UMESP. Professor doutor do programa de pós-graduação em Odontologia (mestrado) - área de concentração em Ortodontia - da UMESP. 
obtenção radiográfica, com um scanner a laser de hélio-neônio, para liberação da energia armazenada sob a forma de luz. O método digital direto oferece algumas vantagens, quando comparado com o método indireto, como obtenção em forma real ou semirreal, requer menor dose de raios $\mathrm{X}$ e não necessita de processamento químico.

Os sistemas digitais (direto e indireto), quando comparados aos convencionais, possibilitam, ainda, a manipulação das imagens, incluindo realce, subtração radiográfica e reconstrução da imagem; compressão, transmissão e armazenamento das imagens em espaço reduzido (comparado com as radiografias convencionais). Entretanto, deve-se considerar que, apesar deste avanço tecnológico, as bases da radiologia odontológica não se alteram com isso. A indicação para exames radiológicos, a estratégia de exame, as regras gerais de radiografar, a proteção contra a radiação e o diagnóstico são amplamente independentes do sistema de recepção de imagem a ser utilizado. Os erros e descuidos neste setor não podem ser anulados pela técnica da radiografia digital.

Considerando-se essas observações, o presente estudo teve como objetivo comparar as radiografias convencionais e digitais, com o intuito de observar a qualidade das imagens e facilidade na marcação das estruturas anatômicas e dos pontos radiográficos.

\section{REVISÃO DE LITERATURA}

Desde que surgiu o primeiro aparelho de raios X dentário, em 1919, os filmes radiográficos têm sido usados com inúmeros propósitos, como: diagnóstico, avaliação de patologias, lesões periapicais, reabsorções dentárias e na avaliação de tratamentos endodônticos e restauradores já existentes.

Nos anos 80, o primeiro sistema digital direto para radiografia intrabucal foi comercializado para Odontologia. Esse sistema usava um computador pessoal (PC) que era, na ocasião, relativamente caro e tinha pequeno espaço de armazenamento, e utilizava um sistema operacional baseado no MSDOS $^{\circledR}$ (Microsoft, EUA), que necessitava de um programa especial - dependente do hardware - para exibir as imagens. Esses problemas foram superados eventualmente pela introdução do Windows $^{\circledR}$ (Microsoft, EUA), que veio a facilitar a visualização das imagens digitais. Foi introduzida, também nos anos 80 , a placa de fósforo fotoativada pelo sistema de radiografia computadorizada Fuji, mas somente em 1996 foi licenciado para a Corporação Soredex (Helsinki, Finlândia). As placas são disponíveis para radiografias intrabucais, panorâmicas e cefalométricas ${ }^{3}$.

Em 1992, Gröndahl' descreveu a utilização da radiografia digital no diagnóstico dentário. Relatou que muitas tecnologias têm sido desenvolvidas para a realização do diagnóstico, mas a aceitação clínica tem sido lenta, devido ao seu alto custo. Questionou se o sistema digital tem relação custo/ benefício que justifique a substituição do sistema convencional. Relatou, ainda, que as imagens obtidas pelo sistema convencional podem ser digitalizadas e armazenadas no computador, e com ambos os sistemas as imagens podem ser processadas e manipuladas. A desvantagem do sistema convencional é a variação da densidade, onde a percepção da imagem é influenciada por vários fatores, sendo alguns parte integrante dessa imagem, outros dependem da observação da imagem.

Segundo Wenzel e Gröndahl13 ${ }^{13}$, as radiografias convencionais vêm sendo cada vez mais substituídas pelas digitais. A facilidade na manipulação, realce, armazenamento e transmissão das imagens digitais estão entre as principais vantagens. O realce das imagens digitais favoreceria a otimização do diagnóstico, ao contrário dos filmes convencionais, que favorecem uma imagem estática, que não pode ser manipulada nem realçada. A manipulação das imagens digitais evitaria repetidas exposições do paciente à radiação, em virtude de cerca de 30\% das exposições repetidas ocorrerem devido à densidade imprópria das imagens.

Em 1996, Forsyth et al. ${ }^{4}$ descreveram as vantagens da radiografia cefalométrica digital sobre a convencional. Segundo esses autores, uma das 
vantagens seria o armazenamento de dados a custos menores e com menor necessidade de espaço. Os dados digitais podem ser armazenados em discos a laser e mídias magnéticas. A visualização das imagens digitais no monitor do computador, por exemplo, seria mais conveniente para o operador. Outra vantagem das radiografias digitais sobre as convencionais é a baixa exposição do paciente à radiação, graças à introdução de técnicas recentes de captura e realce das imagens digitais. A transmissão de imagens digitais de um local para outro mais distante seria facilitada e a automatização evitaria a necessidade de um traçado manual, removendo, assim, a subjetividade do operador.

Forsyth et al. ${ }^{5}$, no mesmo ano, utilizaram 30 telerradiografias laterais com o objetivo de comparar a validade e reprodutibilidade de medidas angulares e lineares de radiografias digitais e das homólogas convencionais. Os resultados do estudo revelaram um erro casual maior nas imagens digitais, comparadas com as convencionais, em 17 das 22 medidas lineares e angulares. Os autores concluíram que as imagens digitais fornecem uma qualidade baixa, quando comparadas com as convencionais. Essa perda de qualidade estaria relacionada à baixa resolução espacial e à relação entre densidade óptica da radiografia e os níveis de cinza das imagens digitais.

Versteeg, Sanderink e Van der Stelt ${ }^{12}$ compararam as radiografias digital e convencional. Em relação à qualidade da imagem, a vantagem do sistema digital é que o contraste e o brilho podem ser automaticamente ajustados. Os sistemas diretos de obtenção das imagens digitais requerem pouca dose de radiação, assim como facilitam o processamento e manipulação da imagem, selecionando apenas os segmentos úteis para o diagnóstico. $\mathrm{O}$ processamento das imagens digitais inclui o realce, a subtração radiográfica, a análise automatizada da imagem e a reconstrução da imagem.

Näslund et al. ${ }^{11}$ analisaram os efeitos da redução de $50 \%$ a $75 \%$ da dose de radiação na localização de pontos cefalométricos em telerradiografias laterais digitais. Foram selecionados, aleatoriamente, 10 pacientes, com média de idades de 14,2 anos. A qualidade das radiografias digitais foi avaliada subjetivamente por 7 observadores da área ortodôntica. Não se observou influência da redução da dose de radiação na localização dos pontos cefalométricos e, consequentemente, na qualidade das radiografias digitais.

Miles, Langlais e Parks ${ }^{9}$ ressaltaram que fatores como o custo elevado dos sistemas digitais, assim como a falta de espaço nos consultórios odontológicos para a instalação dos aparelhos de raios $\mathrm{X}$ para radiografias digitais e a falta de treinamento profissional, estão entre as principais causas da não utilização do sistema digital por parte dos cirurgiões-dentistas.

$\mathrm{Mol}^{10}$ ressaltou as várias propriedades da imagem digital nas radiografias odontológicas. Uma dessas propriedades seria o realce da imagem, que pode ser feito aumentando o contraste, otimizando a claridade (brilho), corrigindo pixels defeituosos ou removendo partes borradas da imagem. Nesse ponto, o realce da imagem se confunde com a propriedade de restauração da imagem. $\mathrm{O}$ autor destaca que a utilização de mensurações digitais em Ortodontia tem facilitado a análise cefalométrica, especialmente quando associada com a localização automatizada dos pontos cefalométricos. A segmentação e a compressão da imagem seriam outras importantes propriedades dos sistemas digitais.

Gijbels et al. ${ }^{6}$ analisaram a eficácia clínica de imagens cefalométricas digitais e convencionais. Foram utilizados 3 cadáveres humanos, submetidos a 9 diferentes exposições. Os resultados revelaram que a qualidade das imagens digitais foi superior àquela das convencionais. As imagens digitais sofreram muito pouca variação entre as exposições, ao contrário das imagens convencionais. Isso revela que pequenas variações na exposição não influenciam a qualidade subjetiva da imagem digital.

Berkhout, Sanderink e Van der Stelt ${ }^{1}$ publicaram uma pesquisa realizada com cirurgiões-dentistas 
holandeses, comparando radiografias digitais e convencionais. Foram utilizados 424 questionários referentes à simpatia e satisfação com as técnicas utilizadas pelos profissionais, assim como a intenção de compra de um sistema digital. Os resultados revelaram que $77 \%$ dos profissionais que utilizavam filmes radiográficos possuíam a intenção de adquirir o sistema digital em seus consultórios. A desvantagem desse sistema, para 50\% dos profissionais, seria o custo muito elevado.

Brennan ${ }^{2}$ publicou um trabalho no qual descreveu os princípios básicos da radiografia digital, assim como suas vantagens e desvantagens. Entre as principais vantagens estariam: a possibilidade de manipulação das imagens, realce do contraste, sobreposição das imagens, armazenamento, redução do tamanho das imagens quando necessário, etc. A principal desvantagem seria o custo elevado, além da possibilidade de infecção cruzada dos pacientes, nos casos de radiografias intrabucais, a manipulação das imagens para fins fraudulentos, etc.

\section{MATERIAL E MÉTODOS}

A amostra para a execução do presente estudo constituiu-se de 30 telerradiografias em norma lateral, sendo 15 convencionais (Fig. 1) e 15 digitais (Fig. 2). As telerradiografias, pertencentes aos arquivos do Programa de Pós-graduação em

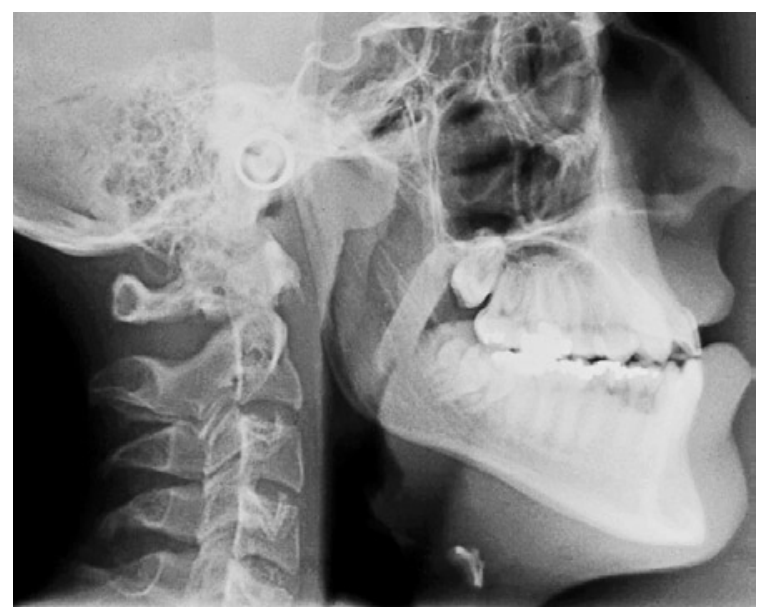

FIGURA 1 - Telerradiografia em norma lateral convencional.
Ortodontia da UMESP, foram obtidas de 15 indivíduos brasileiros, adultos, sendo que de cada paciente obteve-se uma radiografia convencional e uma digital.

As radiografias digitais foram impressas por meio de uma impressora a laser DryPix 1000 (Fujifilm Medical Systems, EUA).

\section{Métodos}

\section{Obtenção do cefalograma}

Os traçados cefalométricos das estruturas cranianas obtidos a partir das radiografias cefalométricas em norma lateral foram realizados manualmente com auxílio de um negatoscópio de mesa de cristal líquido SV 310 (Soligor, Alemanha), em uma sala escurecida, utilizando-se folhas de papel acetato transparente tipo Ultraphan com tamanho de 17,5 x 17,5cm da marca 3M Unitek (Sumaré/SP).

Traçou-se as seguintes estruturas anatômicas (Fig. 3):

1) perfil dos tecidos moles;

2) sela turca;

3) osso esfenoide;

4) perfil do osso frontal e ossos nasais;

5) margens infraorbitais;

6) fossa pterigopalatina;

7) osso maxilar;

8) corpo e cabeça da mandíbula.

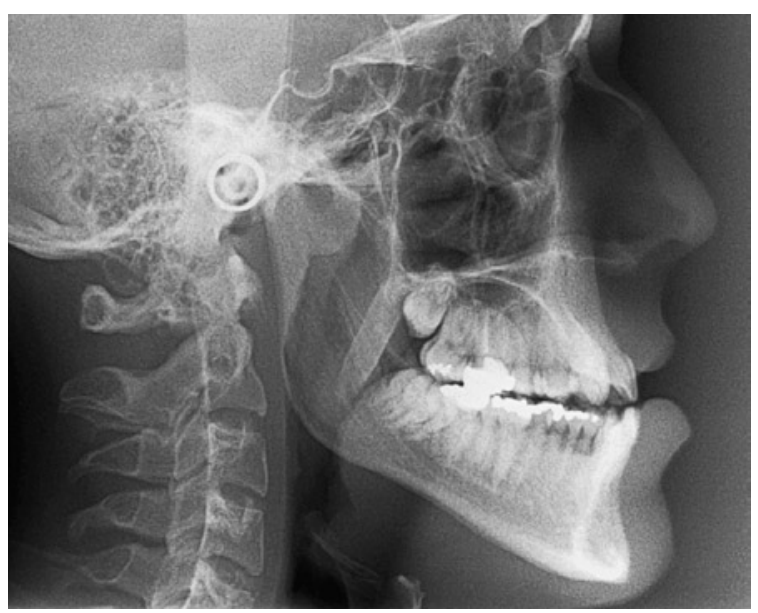

FIGURA 2 - Telerradiografia em norma lateral digital. 


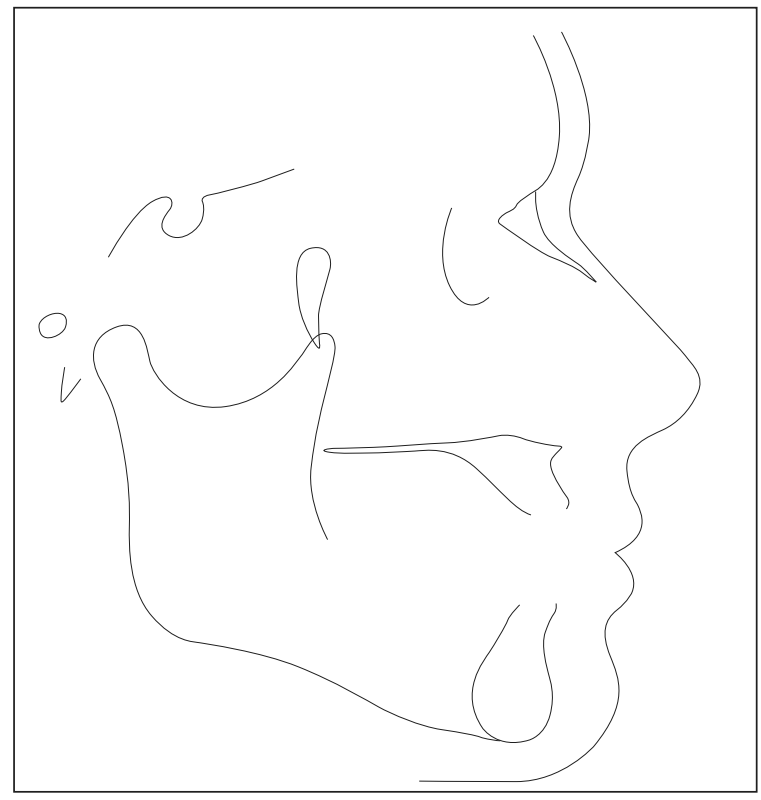

FIGURA 3 - Estruturas anatômicas.

Pontos cefalométricos (Fig. 4)

- Ponto N (Násio): ponto mais anterior da sutura frontonasal.

- Ponto S (Sela): ponto localizado no centro da sela turca.

- Ponto Po (Pório): ponto mais superior do conduto auditivo externo.

- Ponto Or (Orbital): ponto mais inferior do contorno da órbita.

- Ponto A (Subespinhal): ponto médio mais profundo, na concavidade maxilar anterior, entre a espinha nasal anterior (ENA) e o rebordo alveolar.

- Ponto B (Supramentoniano): ponto mais profundo da superfície anterior do contorno da sínfise da mandíbula.

- Ponto Pog (Pogônio): ponto mais anterior da sínfise mandibular, determinado por uma tangente passando pelo násio $(\mathrm{N})$.

- Ponto Prn (Pronasal médio): ponto médio da curvatura da borda inferior do nariz.

- Ponto Sn (Subnasal): ponto localizado no tecido mole, na interseção do sulco labial e da columela nasal.

- Ponto Ls (Lábio superior): ponto mais proe-

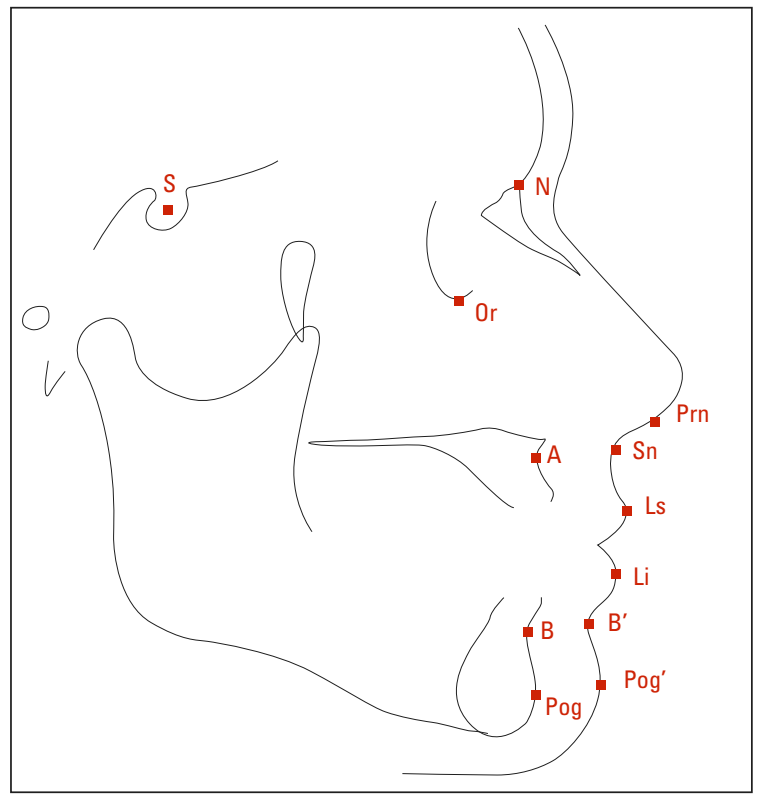

FIGURA 4 - Pontos anatômicos.

minente do lábio superior.

- Ponto Li (Lábio inferior): ponto mais proeminente do lábio inferior.

- Ponto B': ponto mais profundo do perfil.

- Ponto Pog' (Pogônio mole): ponto mais anterior do contorno do mento mole.

Linhas e planos cefalométricos (Fig. 5)

- Linha SN: linha que une os pontos S e N.

- Linha N perp: linha perpendicular ao plano de Frankfurt (Po-Or), passando pelo ponto $\mathrm{N}$ (násio).

- Linha Sn-Prn: linha que une os pontos Sn e Prn.

- Linha Sn-Ls: linha que une os pontos Sn e Ls.

- Linha B'-Li: linha que une os pontos B' e Li.

- Linha B'-Pog': linha que une os pontos B' e Pog'.

- Linha H-nariz: a linha de Holdaway é determinada pela união de um ponto no mento (pogônio mole) e no lábio superior mais proeminente.

- Linha E: o plano estético de Ricketts, representado pela linha $\mathrm{E}$ (pogônio mole-ponta do nariz), descreve a posição do lábio inferior como dois milímetros atrás da linha $\mathrm{E}$. 


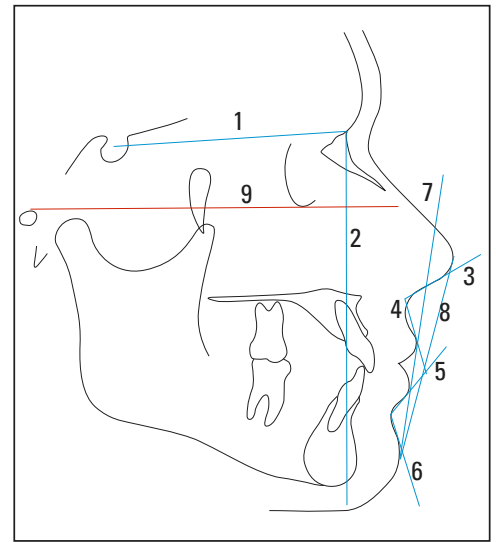

FIGURA 5 - Linhas e planos: 1) linha $S N$, 2) linha $N$ perp, 3) linha Sn-Prn, 4) linha Sn-Ls, 5) linha $B^{\prime}-$ Li, 6) linha $B^{\prime}-$ Pog' $^{\prime}$ 7) linha H-Nariz, 8) linha $E$ e 9) plano horizontal de Frankfurt.

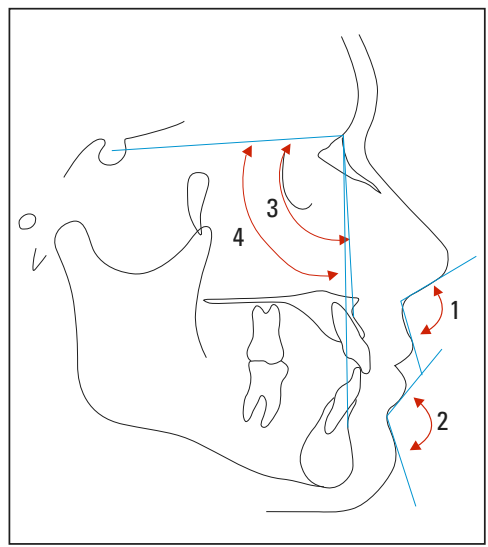

FIGURA 6 - Medidas angulares: 1) ANL, 2) $A M L, 3)$ SNA e 4) SNB.

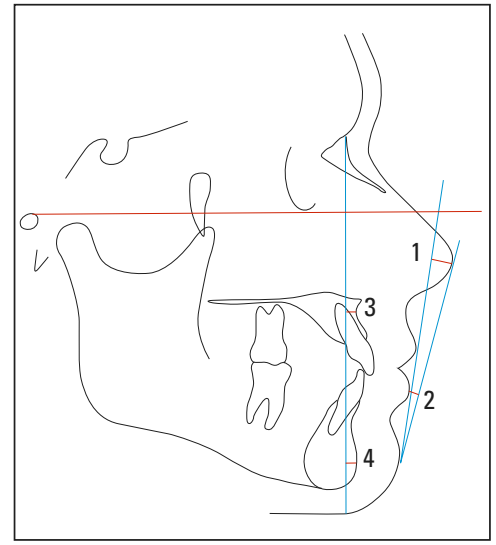

FIGURA 7 - Medidas lineares: 1) linha H-nariz, 2) linha E, 3) Nperp-A e 4) Nperp-Pog.
- Plano horizontal de Frankfurt (PF): formado pela união dos pontos Po (pório) e Or (orbitário).

Após a realização do desenho anatômico, traçou-se as linhas e planos de interesse para o estudo, para o obtenção das medidas lineares e angulares (Fig. 6, 7).

Essas medidas foram expostas em uma planilha do Excel $^{\circledR}$ (Microsoft, EUA) e enviadas para análise estatística. Após 60 dias, as telerradiografias foram retraçadas e remedidas.

Para os dois métodos, foi avaliado o erro na repetição da medição executada pelo mesmo examinador. Para verificar o erro sistemático intraexaminador foi utilizado o teste $t$ pareado. Na determinação do erro casual, utilizou-se o cálculo de erro proposto por Dahlberg (apud HOUSTON ${ }^{8}, 1983$ ):

$$
\text { erro }=\sqrt{\frac{\sum \mathrm{d}^{2}}{2 \mathrm{n}}}
$$

Onde $d=$ diferença entre $1^{a}$ e $2^{a}$ medições e $\mathrm{n}=$ número de radiografias retraçadas.

Para verificar se há diferença estatisticamente significativa entre os dois métodos, foi utilizado o teste $t$ pareado. Para verificar o grau de correlação entre os métodos, foi utilizado o coeficiente de correlação de Pearson. Em todos os testes adotou-se nível de significância de 5\% ${ }^{14}$.

Os testes foram executados no programa Statistica for Windows v. 5.1 (StatSoft Inc., EUA).

\section{RESULTADOS}

Os resultados das avaliações do erro sistemático, avaliado pelo teste t pareado, e do erro casual, medido pela fórmula de Dahlberg, são apresentados na tabela 1 .

A tabela 2 mostra a comparação entre as médias obtidas pelos dois métodos, onde pode-se observar que não houve diferença estatisticamente significativa para nenhuma das medidas estudadas.

A tabela 3 mostra o grau de correlação entre os dois métodos, sendo observada uma forte correlação para todas as medidas estudadas, sendo que a que apresentou menor correlação foi a AML.

\section{DISCUSSÃO}

A análise radiográfica é de fundamental importância para o estabelecimento de um correto diagnóstico, planejamento e tratamento dos casos.

Apesar de alguns inconvenientes da técnica radiográfica convencional - tais como processamento químico e armazenamento -, deve-se convir que os filmes mostram-se como um método acessível e bem aceito para arquivar imagens obtidas. 
TABELA 1 - Média, desvio-padrão das duas medições, teste t pareado e erro de Dahlberg para avaliar o erro sistemático e o erro casual.

\begin{tabular}{|c|c|c|c|c|c|c|c|c|}
\hline \multirow{2}{*}{ TIPO } & \multirow{2}{*}{ MEDIDAS } & \multicolumn{2}{|c|}{$1^{\mathrm{a}}$ MEDIÇÃO } & \multicolumn{2}{|c|}{$2^{\mathrm{a}}$ MEDIÇÃO } & \multirow{2}{*}{$t$} & \multirow{2}{*}{ p } & \multirow{2}{*}{ ERRO } \\
\hline & & média & d.p. & média & d.p. & & & \\
\hline \multirow{8}{*}{ convencional } & ANL & 95,30 & 10,89 & 96,83 & 11,87 & 3,104 & $0,008^{*}$ & 1,70 \\
\hline & AML & 123,23 & 13,88 & 123,87 & 14,35 & 1,475 & 0,162 n.s. & 1,22 \\
\hline & SNA & 79,43 & 3,71 & 79,43 & 3,90 & 0,000 & 1,000 n.s. & 0,26 \\
\hline & SNB & 80,03 & 4,50 & 80,03 & 4,70 & 0,000 & 1,000 n.s. & 0,34 \\
\hline & H-nariz & 10,90 & 4,08 & 10,97 & 3,99 & 0,564 & 0,582 n.s. & 0,32 \\
\hline & linha $E$ & $-2,33$ & 3,18 & $-2,33$ & 3,13 & 0,000 & 1,000 n.s. & 0,26 \\
\hline & Nperp-A & $-0,10$ & 5,28 & 0,20 & 5,29 & 3,674 & $0,003^{*}$ & 0,30 \\
\hline & Nperp-Pog & 5,30 & 11,07 & 5,57 & 10,58 & 1,196 & 0,251 n.s. & 0,62 \\
\hline \multirow{8}{*}{ digital } & ANL & 97,10 & 10,74 & 97,27 & 10,67 & 1,435 & 0,173 n.s. & 0,33 \\
\hline & AML & 126,10 & 14,91 & 125,63 & 14,76 & 2,956 & $0,010^{*}$ & 0,53 \\
\hline & SNA & 79,33 & 3,34 & 79,27 & 3,12 & 0,807 & 0,433 n.s. & 0,22 \\
\hline & SNB & 79,73 & 4,66 & 79,70 & 4,54 & 0,435 & 0,670 n.s. & 0,20 \\
\hline & H-nariz & 11,37 & 4,41 & 11,33 & 4,39 & 0,269 & 0,792 n.s. & 0,33 \\
\hline & linha $\mathrm{E}$ & $-2,50$ & 3,17 & $-2,60$ & 3,14 & 1,382 & 0,189 n.s. & 0,20 \\
\hline & Nperp-A & $-0,10$ & 1,35 & 0,03 & 4,36 & 1,468 & 0,164 n.s. & 0,26 \\
\hline & Nperp-Pog & 5,20 & 8,96 & 5,30 & 8,70 & 0,823 & 0,424 n.s. & 0,33 \\
\hline
\end{tabular}

n.s. = diferença estatisticamente não significativa, ${ }^{*}=$ diferença estatisticamente significativa $(p<0,05)$.

TABELA 2 - Comparação entre as duas técnicas pelo teste t pareado.

\begin{tabular}{|c|c|c|c|c|c|c|c|}
\hline \multirow{2}{*}{ MEDIDAS } & \multicolumn{2}{|c|}{ CONVENCIONAL } & \multicolumn{2}{|c|}{ DIGITAL } & \multirow[b]{2}{*}{ DIFERENÇA } & \multirow[b]{2}{*}{$\mathbf{t}$} & \multirow[b]{2}{*}{$\mathbf{p}$} \\
\hline & média & d.p. & média & d.p. & & & \\
\hline ANL & 95,30 & 10,89 & 97,10 & 10,74 & $-1,80$ & $-1,658$ & 0,119 n.s. \\
\hline AML & 123,23 & 13,88 & 126,10 & 14,91 & $-2,87$ & $-1,106$ & 0,287 n.s. \\
\hline SNA & 79,43 & 3,71 & 79,33 & 3,34 & 0,10 & 0,236 & 0,817 n.s. \\
\hline SNB & 80,03 & 4,50 & 79,73 & 4,66 & 0,30 & 1,235 & 0,237 n.s. \\
\hline H-nariz & 10,90 & 4,08 & 11,37 & 4,41 & $-0,47$ & $-0,902$ & 0,382 n.s. \\
\hline linha E & $-2,33$ & 3,18 & $-2,50$ & 3,17 & 0,17 & 0,471 & 0,645 n.s. \\
\hline Nperp-A & $-0,10$ & 5,28 & $-0,10$ & 4,35 & 0,00 & 0,000 & 1,000 n.s. \\
\hline Nperp-Pog & 5,30 & 11,07 & 5,20 & 8,96 & 0,10 & 0,129 & 0,899 n.s. \\
\hline
\end{tabular}

n.s. = diferença estatisticamente não significativa.

Radiografias com boa qualidade podem, ainda, ser digitalizadas e armazenadas no computador.

Hoje, com o surgimento das radiografias digitais, pode-se obter imagens instantâneas utilizando um menor tempo de exposição, graças à introdução de técnicas recentes de captura e realce das imagens, maior facilidade na manipulação das imagens e facilidade de transmissão dessas imagens digitais de um lugar para outro mais distante, além do armazenamento dos dados a custos menores e com necessidade de menor espaço $\mathrm{o}^{2,4,7,12,13}$. Outras vantagens obtidas são: dispensa do processamento 
TABELA 3 - Coeficiente de correlação de Pearson entre os dois métodos.

$\begin{array}{ccc}\text { medidas } & \mathbf{R} & \mathbf{p} \\ \text { ANL } & 0,92 & <0,001^{*} \\ \text { AML } & 0,76 & 0,001^{*} \\ \text { SNA } & 0,90 & <0,001^{*} \\ \text { SNB } & 0,98 & <0,001^{*} \\ \text { H-nariz } & 0,89 & <0,001^{*} \\ \text { linha E } & 0,91 & <0,001^{*} \\ \text { Nperp-A } & 0,91 & <0,001^{*} \\ \text { Nperp-Pog } & 0,98 & <0,001^{*}\end{array}$

* $=$ correlação estatisticamente significativa $(p<0,05)$.

químico necessário nos filmes radiográficos e a possibilidade de alterar o contraste e o brilho dessas imagens ${ }^{10,12}$.

Näslund et al. ${ }^{11}$ analisaram os efeitos da redução de $50 \%$ a $75 \%$ da dose de radiação na localização de pontos cefalométricos em telerradiografias laterais digitais. Foram selecionados, aleatoriamente, 10 pacientes, com média de idade de 14,2 anos. A qualidade das radiografias digitais foi avaliada subjetivamente por 7 observadores da área ortodôntica. Não se observou influência da redução da dose de radiação na localização dos pontos cefalométricos e, consequentemente, na qualidade das radiografias digitais. Em contrapartida, Gijbels et al. ${ }^{6}$ observaram a eficácia clínica de imagens cefalométricas digitais e convencionais. Para isso, utilizaram 3 cadáveres humanos, submetidos a 9 diferentes exposições. Os resultados revelaram que a qualidade das imagens digitais foi superior à das convencionais. As imagens digitais sofreram muito pouca variação entre as exposições, ao contrário das imagens convencionais. Isso revela que pequenas variações na exposição não influenciam a qualidade subjetiva da imagem digital. Fatores como o custo elevado dos sistemas digitais, assim como a falta de espaço nos consultórios odontológicos para a instalação dos aparelhos de raios X e a falta de treinamento profissional, estão entre as principais causas da não utilização do sistemas digitais por parte dos cirurgiões-dentistas ${ }^{1,2,9}$.

Em nosso estudo, considerando os resultados obtidos entre a comparação das duas técnicas radiográficas pelo teste t pareado, observou-se que não houve diferença estatisticamente significativa, discordando dos resultados obtidos no estudo de Forsyth et al. ${ }^{4}$, no qual um erro casual maior nas imagens digitais foi encontrado, quando comparadas com as convencionais.

No presente estudo, quando analisadas separadamente as duas técnicas, a técnica convencional apresentou uma diferença estatisticamente significativa em duas medidas (ANL e Nperp-A), provavelmente devido à superexposição ou subexposição no processamento químico, devido à temperatura. Com relação à técnica digital, apenas a medida AML apresentou diferença estatisticamente significativa. Segundo Forsyth et al. ${ }^{4}$, as imagens digitais apresentam uma perda na qualidade que estaria relacionada à baixa resolução espacial e à relação entre densidade óptica da radiografia e os níveis de cinza das imagens digitais.

Quando analisado o grau de correlação entre os dois métodos, pode-se observar uma forte correlação para todas as medidas estudadas, sendo que a que apresentou menor correlação foi a medida AML.

\section{CONCLUSÃO}

Com base nos dados obtidos, pode-se observar que não houve diferença estatisticamente significativa quando comparados os 2 métodos de estudo (convencional e digital). Assim como na correlação entre os 2 métodos, notou-se uma forte correlação para todas as medidas estudadas.

Sendo assim, pode-se concluir que independentemente do método aplicado, o indivíduo que realiza o traçado, seja manual ou por meio de programas de computador, tanto na radiografia convencional quanto na digital, deve estar treinado e calibrado para a execução do mesmo.

\section{AGRADECIMENTOS}

Ao Sr. Mauro Gondo, pelo suporte técnico nesse trabalho.

Enviado em: setembro de 2006 Revisado e aceito: janeiro de 2007 


\title{
Qualitative evaluation between conventional and digital lateral cephalograms
}

\begin{abstract}
Aim: This study aimed to evaluate, by cephalometric tracing and measurements, the difficulty in the localization of structures and points on both conventional and digital lateral cephalograms. Methods: The sample comprised 30 lateral cephalograms, being 15 conventional and 15 digital. These radiographs were taken from 15 Brazilian adult subjects, with achievement of one conventional and one digital cephalogram for each subject. Results: The obtained data revealed no statistically significant difference between the two study methods. Conclusion: Thus, it was concluded that, regardless of the utilized method, the professional performing the cephalometric tracing, either manually or with a computer software, should be well trained and calibrated for that.
\end{abstract}

Keywords: Cephalometric radiography. Conventional radiography. Digital radiography.

\section{REFERÊNCIAS}

1. BERKHOUT, W.; SANDERINK, G. C. H.; VAN DER STELT, P. F. A comparison of digital and film radiography in Dutch dental practices assessed by questionnaire. Dentomaxillofac. Radiol., Houndsmills, v. 31, no. 2, p. 93-99, Mar. 2002.

2. BRENNAN, J. A introduction to digital radiography in Dentistry. J. Orthod., London, v. 29, p. 66-69, 2002.

3. FARMAN, A.; FARMAN, T. Extraoral and panoramic systems. Dent. Clin. North Am., Philadelphia, v. 44, no. 2, p. 257-272, Apr. 2000.

4. FORSYTH, D. B. et al. Digital imaging of cephalometric radiography, part 1: advantages and limitations of digital imaging. Angle Orthod., Appleton, v. 66, no. 1, p. 37-42, 1996.

5. FORSYTH, D. B. et al. Digital imaging of cephalometric radiography, part 2: image quality. Angle Orthod., Appleton, v. 66, no. 1, p. 43-50, 1996.

6. GIJBELS, F. et al. Diagnostic yield of conventional and digital cephalometric images: a human cadaver study. Dentomaxillofac. Radiol., Houndsmills, v. 30, p. 101-105, 2001.

7. GRÖNDAHL, H. G. Digital radiology in dental diagnosis: a critical view. Dentomaxillofac. Radiol., Houndsmills, v. 21, p. 198-202, 1992.
8. HOUSTON, W. J. B. The analysis of errors in orthodontic measurements. Am. J. Orthod., St. Louis, v. 83, no. 5, p. 382-390, 1983

9. MILES, D. A.; LANGLAIS, R. P.; PARKS, E. T. Digital X-rays are here. Why aren't you using them? CDA J., Los Angeles, v. 27, no. 12, p. 926-934, 1999.

10. $\mathrm{MOL}, \mathrm{A}$. Image processing tools for dental applications. Dent. Clin. North Am., Philadelphia, v. 44, no. 2, p. 299-318, 2000.

11. NÄSLUND, E. B.; KRUGER, M.; PETERSSON, A.; HANSEN, K. Analysis of low-dose digital lateral cephalometric radiographs. Dentomaxillofac. Radiol., Houndsmills, v. 27, p. 136-139, 1998

12. VERSTEEG, C. H.; SANDERINK, G. C. H.; VAN DER STELT, P. F. Efficacy of digital intra-oral radiography in clinical Dentistry. J. Dent., Bristol, v. 25, no. 3-4, p. 215-224, 1997.

13. WENZEL, A.; GRÖNDAHL, H. G. Direct digital radiography in the dental office. Int. Dent. J., London, v. 45, p. 27-34, 1995.

14. ZAR, J. H. Biostatistical analysis. 3rd ed. New Jersey: PrenticeHall, 1996.
Endereço para correspondência
Tatiana Sumie Kawahara Abrahão
Av. Nove de Julho, 290 - Centro
CEP: $16.430-000$ - Guaiçara / SP
E-mail: tatikawahara@hotmail.com 